\title{
BARCODING THE SPECIES OF PLEUROTHALLIS SUBSECTION MACROPHYLLAE-FASCICULATAE
}

\author{
MARK WILSON \\ Biology Department, The Colorado College, Colorado Springs, CO 80903, USA \\ mwilson@coloradocollege.edu
}

The long-term goal of this project is to have a genetic "barcode" for the described species in Pleurothallis subsection Macrophyllae-Fasciculatae (syn. Acronia Luer) to facilitate identification, recognition of new species, biodiversity assessment, and conservation of this genus in Mesoamerica and the Andes. To this end, a living collection is being assembled at Colorado College with plants from commercial operations in South America (Ecuagenera; Colomborquídeas; Orquídeas del Valle) and the U.S. (Andy's Orchids; Hanging Gardens; J \& L Orchids); and private collections in the U.S. (O'Shaughnessy). As these plants flower and identities are confirmed, photos are taken; in the future, herbarium sheets will be prepared and flowers preserved in spirits. For some species, or from some locations such as Central America (private collection of Archila), only leaf samples have been obtained. Between living plants and leaf samples $\sim 100$ different species have been assembled, which is approximately $46 \%$ of the described species. A genetic barcode for this subsection of Pleurothallis will likely consist of three sequences. While only nrITS has been sequenced for these plants so far, the chloroplast sequences rpoB2, rpoC1, and the 3' and 5 ' ends of $y c f 1$ are currently being investigated to determine which provide greatest variability, perhaps to combine with matK or trnH-psbA as per the CBOL Plant Working Group. 